\title{
Evaluation of Brain Targeting and Mucosal Integrity of Nasally Administrated Nanostructured Carriers of a CNS Active Drug, Clonazepam
}

\author{
Hend Mohamed Abdel-Bar', Amal Youssef Abdel-Reheem ${ }^{1}$, Gehanne Abdel Samie Awad ${ }^{2}$, Nahed Daoud Mortada² \\ ${ }^{1}$ Department of Pharmaceutics, National Organization of Drug Control and Research, Giza, Egypt. ${ }^{2}$ Department of \\ Pharmaceutics and Industrial Pharmacy, Faculty of Pharmacy, Ain Shams University, Cairo, Egypt.
}

Received, April 4, 2013; Revised, May 8, 2013; Accepted, June 21, 2013; Published, June 23, 2013.

\begin{abstract}
PURPOSE: The aim of the study was to target clonazepam, a CNS active drug, to the brain through the non-invasive intranasal (in) route using of nanocarriers with proven safety METHOD: in clonazepam nanocarriers were prepared by mixing isopropyl myristate, Tween 80, Cremophor EL or lecithin, polyethylene glycol 200, propylene glycol or ethanol in different ratios with water. in-vitro characterization of the nanocarriers was done by various methods including: polarized light microscopy, particle size determination, viscosity measurements and drug release studies. in-vivo study comparing intranasal and intravenous administration was performed. The drug targeting efficiency (DTE \%) and direct nose to brain transport percentage (DTP \%) were calculated and nasal integrity assessment was carried out. RESULTS: The obtained formulae had particle size below $100 \mathrm{~nm}$ favoring rapid direct nose to brain transport and the time for $100 \%$ drug release $\left(\mathrm{T}_{100 \%}\right)$ depended on systems composition. Plasma $\mathrm{T}_{\max }$ of clonazepam nanostructured carriers varied from 10-30 min., while their brain $\mathrm{T}_{\max }$ did not exceed $10 \mathrm{~min}$, in comparison with $30 \mathrm{~min}$ for $i v$ solution. Although there was no significant difference $(\mathrm{p}>0.05)$ between the plasma $\mathrm{AUC}_{0-\infty}$ of the different tested nanocarriers and intravenous one, the increase in brain $\mathrm{AUC}_{0-\infty}$ of different nasal formulations in comparison to that of $i v$ administration (3.6 -7.2 fold) confirms direct nose to brain transport via olfactory region. Furthermore, DTE and DTP\% confirmed brain targeting of clonazepam following intranasal administration. CONCLUSION: The results confirmed that intranasal nanocarriers were proved to be safe alternative for $i v$ clonazepam delivery with rapid nose to brain transport.
\end{abstract}

This article is open to POST-PUBLICATION REVIEW. Registered readers (see "For Readers") may comment by clicking on ABSTRACT on the issue's contents page.

\section{INTRODUCTION}

Blood brain barrier (BBB) behaves as a biochemical barrier that expresses several cytosolic enzymes, which along with efflux pglycoprotein system help in effluxing drugs back into the blood (1). Some of the surfactants, by virtue of their permeation enhancement activity, have the property of increasing BBB uptake due to transient opening of cell junctions (2). In addition, some of them like Cremophores had shown to inhibit P-glycoprotein activity (3).

Parenterally administered nanocarriers such as liposomes, solid lipid nanoparticles, lipid nanocapsules, ethosomes, nanosuspensions and microemulsions have lately found wide medical applications (4). Surfactants, present as major components of some carriers, have been used to improve drug stability, absorption, and clinical potency (5). From the structural point of view, surfactant based systems exhibit a variety of thermodynamic stable phases with a wide range of domain size from nanometers to micrometers as emulsion, microemulsions (ME), liquid crystal (LC) or micelles (6).

The parenteral use of ME to enhance drug uptake by the brain have been reported (7). Lecithin organogels (microemulsion-based gels), are readily formed by adding a minimal amount of a polar solvent (e.g. water) to a solution of lecithin in organic solvent. Lecithin was used for the preparation of liposomes and polymeric micelles for brain targeting via parental administration (8).

Liquid crystalline phase which is an intermediate phase between the crystalline solid and the liquid phase is associated with microemulsions and often exists on the phase

Corresponding Author: Gehanne Abdel Samie Awad Department of pharmaceutics and industrial pharmacy, faculty of pharmacy, Ain Shams University, Cairo, Egypt. Monazzamet El-wehda Elafrikeya Street, Abbasseya, Cairo, Egypt; Email: gawad@pharma.asu.edu.eg 
boundary of the latter. In pharmaceutical field, liquid crystals offer considerable scope for application as drug delivery systems. They have the potential for controlled release, low toxicity and mucoadhesion (9). Therefore, it could have wide range applications of administration regimens including oral, transdermal and parenteral delivery (10-12).

Transnasal route is a non-invasive strategy that can traverse the BBB, to target drug substances and peptides directly to the CNS e.g. sertaline, respiridone, olanzapine, rivastigmine and 17-beta-estradiol (13-16). Better brain targeting can also be achieved by direct movement of drug from the nasal submucosa space into the cerebrospinal fluid (CSF) compartment of brain (17). The highly permeable nasal mucosa allows rapid drug absorption due to high total blood flow, porous endothelial membrane and large surface area, in addition to avoidance of first-pass metabolism (18).

Benzodiazepines are reported to be rapidly absorbed and transported across the mucosa of the nasal sinuses (19) resulting in fast achievement of effective plasma levels. Hence, they can be useful for seizure control. Clonazepam is preferred, over other benzodiazepine, due to its longer duration of action (24 h). Hence, it was chosen in our study as an example for a CNS active drug to be delivered from various nasal nanocarriers. To our knowledge, the literature lacks the use of lecithinbased organogels and or liquid crystals for brain targeting, via the nasal route and no correlation between nanocarrier structure and brain targeting had been reported. Since surfactant based systems represent a major concern regarding safety, nasal integrity assessment was also carried out.

\section{METHODS}

\section{Materials}

Clonazepam and tetrazepam were supplied from Sigma pharmaceutical company Egypt, isopropyl myristate(IPM), Cremophor EL and potassium dihydrogen orthophosphate were purchased from Fluka Chemika-BioChemika Switzerland, phospholipid (egg lecithin), polyoxyethylene 20 sorbitan monooleate (Tween 80), propylene glycol (PG) and polyethylene glycol 200 (PEG200) were purchased from Sigma-Aldrich Company, St. Louis, USA, acetonitrile and absolute alcohol both HPLC grade were purchased from Riedel-de Haen Gmbh, Germany.

\section{Phase diagram construction}

Pseudo-ternary phase diagram was constructed using mixtures of oil (IPM), surfactant (Tween 80 or Cremophor EL) and cosurfactant (PG or PEG200) at different weight ratios (each including $1 \% \mathrm{w} / \mathrm{w}$ clonazepam.) Each point system was diluted with water in a drop wise manner, and vortexed for 30 seconds (20). This gave four systems according to $1 * 2 * 2$ factorial design. Different regions in the phase diagram were identified by visual inspection for clarity and fluidity. The nanocarriers were selected at the desired component ratios from each system (Figure 1).

\section{Preparation of lecithin organogel based microemulsions}

Clonazepam, in $1 \% \mathrm{w} / \mathrm{w}$ concentration, was incorporated into organogel matrix consisting of lecithin, as gelator molecule, in combination with different ratios of Tween 80, a nonpolar organic solvent (IPM) and a polar one (ethanol and water). The different combinations are listed in (Table 1).

\section{in-vitro characterization of clonazepam systems:}

\section{Polarized light microscope study}

Selected viscous formulae were examined by polarized light microscope (Kyowa Optical, Japan) to reveal the formation of liquid crystal if any.

\section{Viscosity determination}

The viscosity of $1 \mathrm{ml}$ sample volume of each of selected formulae was evaluated at $35^{\circ} \mathrm{C}$ using Brookfield DV-III (USA) ultra programmable cone and plate rheometer, fitted with a spindle number 40. Brookfield Rheocalc operating software was controlling the rheometer.

\section{Particle size determination}

Selected nanocarriers were subjected to particle size measurement using Horiba laser scattering particle size distribution analyzer model (LA-920Japan). Mean particle size, $\mathrm{D}_{90 \%}$ and polydispersity index (PDI) were determined.

\section{Conductivity measurement}

The electric conductivity of the selected microemulsions was measured at $35 \pm 0.1^{\circ} \mathrm{C}$ with portable digital conductemeter (Hanna, Hungaria). 
Table 1. Different combinations for organogel microemulsions preparations.

\begin{tabular}{|c|c|c|c|c|c|c|}
\hline \multirow[t]{2}{*}{$\begin{array}{l}\text { System } \\
\text { code }\end{array}$} & \multirow{2}{*}{$\begin{array}{l}\text { IPM weight } \\
(\mathrm{mg})\end{array}$} & \multicolumn{2}{|c|}{$\begin{array}{l}\text { Surfactants } \\
\text { weight (mg) }\end{array}$} & \multicolumn{2}{|c|}{$\begin{array}{l}\text { Polar solvents weight } \\
\text { (mg) }\end{array}$} & \multirow[t]{2}{*}{$n_{w}$} \\
\hline & & $\begin{array}{c}\text { Tween } \\
80\end{array}$ & Lecithin & Water & Ethanol & \\
\hline IMa1 & \multirow{3}{*}{100} & 400 & 400 & 200 & 100 & 0.75 \\
\hline IMa2 & & 534 & 267 & 300 & 100 & 1.5 \\
\hline IMa3 & & 600 & 200 & 500 & 100 & 3 \\
\hline IMb1 & \multirow{3}{*}{200} & 350 & 350 & 200 & 100 & 0.85 \\
\hline IMb2 & & 467 & 233 & 300 & 100 & 1.7 \\
\hline IMb3 & & 525 & 175 & 400 & 100 & 2.8 \\
\hline IMc1 & \multirow{3}{*}{300} & 300 & 300 & 100 & 100 & 0.66 \\
\hline IMc2 & & 400 & 200 & 100 & 100 & 1 \\
\hline IMc3 & & 450 & 150 & 100 & 100 & 2 \\
\hline
\end{tabular}

An amount equivalent to $20 \mathrm{gm}$ of each of microemulsion was accurately weighed and transferred to a glass beaker with a suitable volume, dipped in a water bath adjusted at temperature of $35 \pm 0.1^{\circ} \mathrm{C}$. Each formula was titrated with distilled water in $10 \%$ increments. The electrode was dipped in the microemulsion sample, after each water addition, until equilibrium. The recorded readings were those stable for 20 minutes.

\section{Differential Scanning Calorimetric measurement (DSC)}

Selected formulae were subjected to DSC measurement using DSC-60 Shimadzu differential scanning calorimeter (Japan). Samples (about $6 \mathrm{mg}$ ) were weighed, sealed and subjected to the following procedure: rapid cooling from ambient to $-60^{\circ} \mathrm{C}$, using liquid nitrogen at flow rate $20 \mathrm{ml} / \mathrm{min}$, keeping at this temperature for 5 $\mathrm{min}$, then heating to $60^{\circ} \mathrm{C}$ at a rate of $\quad 5^{\circ}$ $\mathrm{C} / \mathrm{min}$

\section{Drug release}

The method of Zhang et al., (21) using USP dissolution testing apparatus (I) was adopted. Formulae equivalent to $2 \mathrm{mg}$ clonazepam were instilled into closely sealed dialysis bag (Spectra/Por ${ }^{\circledR}$ CE cut off MWCO1000Da,Flat width $8 \mathrm{~mm}$ and diameter $5 \mathrm{~mm}$ ), attached to the shaft of dissolution tester and suspended in 250 $\mathrm{ml}$, phosphate buffer ( $\mathrm{pH} 6.5$ ) adjusted at $35 \pm 0.5^{\circ}$ $\mathrm{C}$, the reported nasal mucosa temperature (22) and the shafts rotated at $50 \pm 0.1 \mathrm{rpm}$. Samples were withdrawn out at predetermined time intervals and replaced by the same volume of fresh dissolution medium. Drug concentration was determined spectrophotometrically at 254 nm. Blank experiment using plain formulae was carried out at the same times and conditions.

The release data of liquid crystal formula and organogel formula were analyzed by Peppas equation (23) to determine the mechanism and order of drug release:

\section{$\mathbf{M}_{\mathbf{t}} / \mathbf{M}=\mathbf{K t}^{\mathrm{n}} \quad$ Equation 1}

Where $M_{t} / M$ is the fraction of drug that has been released at time $t, K$ is a kinetic constant and $\mathrm{n}$ is the diffusional exponent related to the release mechanism . The constant $\mathrm{n}$, equals 0.5 for diffusional (Fickian) release, 1 for zero-order kinetics and $0.5<\mathrm{n}<1$ for anomalous (nonFickian) release.

\section{Effect of storage}

The effect of six months storage in appropriate incubator (HMG-HTC10, India) at $40 \pm 2^{\circ} \mathrm{C}$ and $75 \pm 5 \%$ RH was studied on the selected formulae by visual examination for clarity and phase separation, particle size measurement and drug release.

\section{in-vivo pharmacokinetic, brain distribution} and safety studies

\section{Animals, dosing and administration}

According to the experimental procedures conformed to the ethical principles of "Experiments and Advanced Pharmaceutical Research Unit", as approved by the Faculty of Pharmacy, Ain Shams University on the use of animals Committee, male albino rats (aged 4-5 months) and weighing between 200 to $250 \mathrm{~g}$ were anaesthetized using $50 \mathrm{mg} / \mathrm{kg}$ ketamine intramuscularly. The animals were randomly divided into 5 groups; each of 66 rats to have six 
rats for each time interval. A volume of $10 \mu \mathrm{L}$ of different formulae containing $0.04-0.05 \mathrm{mg}$ clonazepam (equivalent to $0.2 \mathrm{mg} / \mathrm{kg}$ body weight) was administered in each nostril. Formulations were instilled into the nostrils with the help of $(2-20 \mu \mathrm{L})$ high performance micropipette (Robfield-Gmbtt Kobenicker, Strabe 320 Deutsch Land) to which tips, of $0.1 \mathrm{~mm}$ in diameter at the delivery site, were fixed .The rats were held from the back, in slanted position, during in administration (24). For comparison, iv clonazepam solution, with the same dose, was injected through the tail vein of the rats. Briefly, the tail was rotated till visualization of one the veins, the site of injection was disinfected with isopropyl alcohol and the needle (27-30 gauge) inserted into the vein at a slight angle. The injection was done slowly to watch for lumen clearing. Upon injection, the fluid will flow easily into the vein, and the vein will become clear (changing from dark to light) as the fluid temporarily replaces the blood. Complete liquid drainage was ensured after each proper injection (were no bulging of the vein was noticed).

Biodistribution studies of clonazepam formulae following in and $i v$ administration were performed over a period of $8 \mathrm{~h}$. For each formula, at each time interval, six rats were sacrificed. Blood samples taken by cardiac puncture, were put into EDTA containing test tubes and centrifuged at $805 \times g$ for $15 \mathrm{~min}$. Subsequently, the rats were subjected to brain dissection and the isolated brains were washed twice using normal saline, made free from adhering tissue or fluid, and weighed. After collection, all biological samples (plasma and brain tissue) were immediately stored at $-40^{\circ} \mathrm{C}$ until analysis.

\section{Plasma treatment}

Each sample $(500 \mu \mathrm{L})$, mixed with $200 \mu \mathrm{L}$ of internal standard (tetrazepam $100 \mathrm{ng} / \mathrm{mL}$ ) and300 $\mu \mathrm{L}$ of acetonitrile was vortex-mixed for $30 \mathrm{~s}$ and centrifuged at $7245 \times g$ for $10 \mathrm{~min}$. The supernatant was analyzed for drug content using HPLC.

\section{Brain treatment}

The collected brain tissues were homogenized in water using Tissue Homogenizer (VirTis, USA) at 25,000 rpm for one minute. Brain homogenates were treated as mentioned above for plasma samples.

\section{Chromatographic conditions}

HPLC system consisted of DIONEX-Ultimate 3000 (Germany) controlled by Chromeleon 7 Chromatography Data System. The HPLC system was equipped with LPG-3400RS pump and UV detector (VWD-3400RS). A reverse phase C18 column (Thermo ${ }^{\circledR}$ BDS, 250X4.6 mm, $5 \mu$ ) was used at $20^{\circ} \mathrm{C}$. The wavelength of the UV detector was set at $313 \mathrm{~nm}$. Mixture of acetonitrile and 20 $\mathrm{mM}$ phosphate buffer solution $\mathrm{pH} 7(55: 45, \mathrm{v} / \mathrm{v})$ was used as mobile phase at a flow rate of 2 $\mathrm{mL} / \mathrm{min}$. Calibration curves in plasma samples and brain homogenate were constructed in the respective ranges of $5-750 \mathrm{ng} / \mathrm{mL}$ and $10-2500$ $\mathrm{ng} / \mathrm{mL}$; the respective coefficients of determination were $\mathrm{R}^{2}>0.9956$ and $\mathrm{R}^{2}>0.9971$ $(n=6)$ and the respective low limit of quantification (LLOQ) were $5 \mathrm{ng} / \mathrm{mL}$ and $7 \mathrm{ng} / \mathrm{mL}$. The $\mathrm{CV} \%$ values were under $5 \%$. The accuracy for clonazepam determinations in both plasma and brain were within acceptable range (not more than $6 \%$ ) with respective mean $\%$ drug recoveries 97.3 and $94.2 \%$.

\section{Calculations}

Drug concentration data in plasma and brain samples were dose- and weight normalized and analyzed using Wagner-Nelson Method (25) for pharmacokinetics determination. DTE $\%$ and $\mathrm{DTP} \%$ were calculated using the following equations (24);

$$
\begin{aligned}
& \mathrm{DTE} \%=\left(\mathrm{AUC}_{\mathrm{brain}} / \mathrm{AUC}_{\text {blood }}\right) \text { in } /\left(\mathrm{AUC}_{\mathrm{brain}} /\right. \\
& \left.\mathrm{AUC}_{\text {blood }}\right) i v \times 100 \quad \text { Equation } 2 \\
& \mathrm{DTP} \%=[(\mathrm{Bin}-\mathrm{Bx}) / \mathrm{Bin}] \times \mathbf{1 0 0} \\
& \text { Equation } 3
\end{aligned}
$$

Where $\mathrm{B}_{\mathrm{X}}=(\mathrm{B} i v / \mathrm{P} i v \times \mathrm{P} i n)$. It is the brain $\mathrm{AUC}_{0-}$ 480 fraction contributed by systemic circulation, following in administration,

$\mathrm{B} i v$ is the brain $\mathrm{AUC}_{0-480}$ following $i v$ administration,

P $i v$ is the plasma $\mathrm{AUC}_{0-480}$ following $i v$ administration,

Bin is the brain $\mathrm{AUC}_{0-480}$ following in administration,

Pin is the plasma $\mathrm{AUC}_{0-480}$ following in administration.

\section{Nasal irritation test}

Nasal irritation test was done according to the method described by Miyamoto et al. (26). Briefly, male albino rats weighing 250-300 g 
were sedated with an intra-peritoneal injection of thiopental $(45 \mathrm{mg} / \mathrm{kg})$ before each dosing to facilitate nasal administration. Each rat received once daily nasal administration of $10 \mu \mathrm{l}$ of each formula for 14 days, after which, the rats were sacrificed and the nasal septum with the epithelial cell membrane on each side was carefully separated from the bone. The septum was fixed with $10 \%$ formalin, washing was done under tap water, and then serial dilutions of alcohol (methyl, ethyl and absolute ethyl) were used for dehydration. Specimens were cleared in xylene and embedded in paraffin at $56^{\circ} \mathrm{C}$ in hot air oven for twenty-four hours. Paraffin bees wax tissue blocks were prepared for sectioning at 4 microns by slide microtome. The obtained tissue sections were collected on glass slides, deparaffinized and stained by hematoxylin and eosin stain and then examined through the electric light microscope (Euromex, The Netherlands) (27).

\section{Statistical analysis}

All presented data are the mean of three replicates for each in-vitro $\pm \mathrm{SD}$ experiment and six replicates for the in-vivo experiments \pm SD. Student $t$ test was used for comparing between two variables and one way ANOVA followed by Newman-Keuls test was applied to compare between groups. $P$ value $<0.05$ was considered significant. SPSS ${ }^{\circledR}$ software version 7.5 (SPSS Inc., Chicago, IL) was used.

To estimate the associated variability of AUC values of the pooled data that inherently yield one single value for each group, the approach reported by Yuan (28) was used.

Release profiles were considered similar when the similarity factor (F2) value is $\geq 50$ (29).

$$
\mathbf{F}_{2}=50 * \log \left\{\underset{\text { Equation } 4}{\left.\left[1+(1 / n)\left(R_{t}-T_{t}\right)^{2}\right]^{-0.5} * 100\right\}}\right.
$$

\section{RESULTS}

\section{Phase diagram construction}

The pseudo-ternary phase diagrams are displayed in Figures 1. Three of the tested systems were able to form microemulsions. The selected formulae are presented in (Table 2). In each diagram, it is obvious that the microemulsion region was positioned towards surfactant rich zone. Smaller domain areas are noticed with Cremophor EL than with Tween 80, especially in combination with PEG 200.
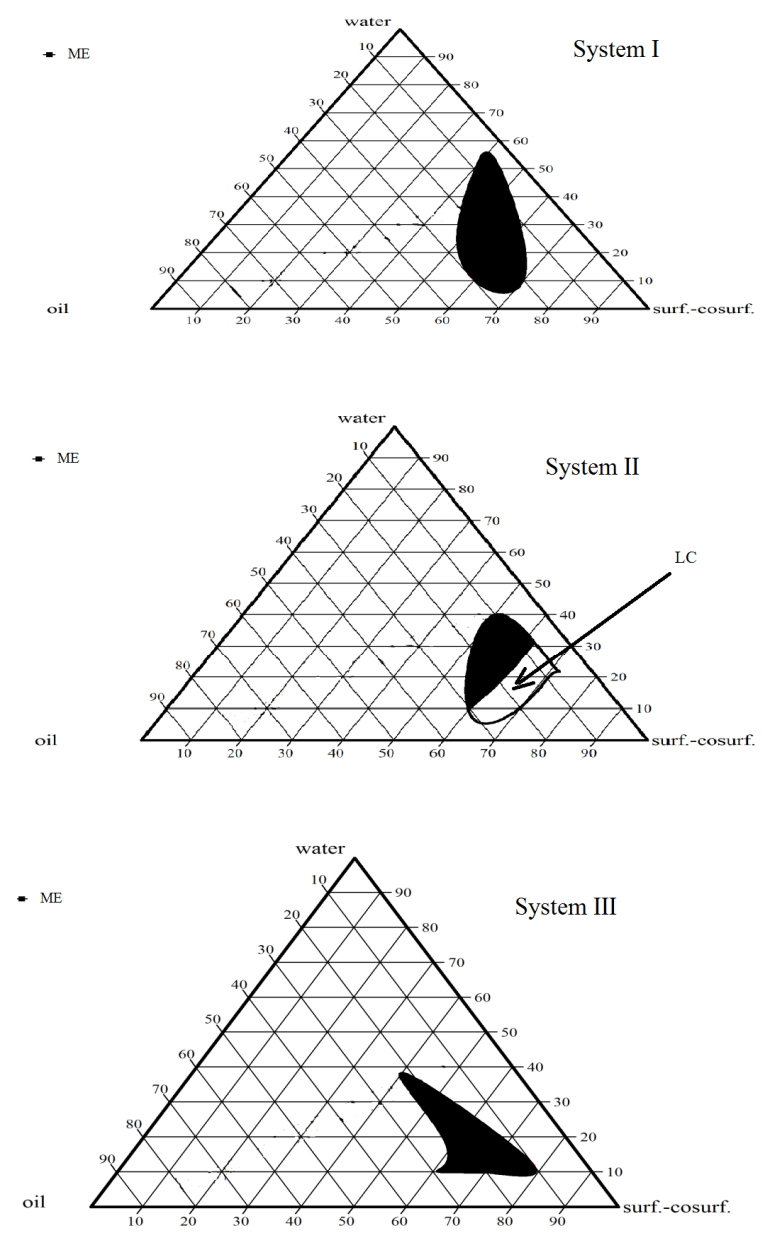

Figure 1. Pseudo ternary phase diagrams of systems I, II and III.

\section{Lecithin organogel based microemulsion}

Based on the obtained phase diagrams (data not shown), the different ratios between polar solvents (water and ethanol) to lecithin weights ( $n_{w}$ values) of different formulae were calculated. Whatever the weight of surfactants used, the highest $n_{w}$ was at 3:1 Tween 80 to lecithin ratio (formula IMa3).

\section{in- vitro characterization of clonazepam formulae}

Polarized light microscope examination (Figure 2) reveals formation of rosette shaped liquid crystal in case of formula II only.

Table 3 shows that microemulsion formula III has a lower viscosity value than formula I and both formulae show viscosity values less than those of formulae II and IMa3. Furthermore, the prepared systems have particle size in the nanorange and can be ascendingly arranged as 
follows: formula $\mathrm{I}<$ III $<$ IMa3 $<$ II going parallel with the water to surfactant ratio (Table 2). The polydispersity indices (PDI) of the prepared formulae are relatively small.

Formula III exhibit very low conductivity value in comparison with formula I (Table 3). Deeper insight about phase changes of the microemulsion in formula I was carried out by DSC study.

Effect of different dilutions on formula I shows that both 20 and $30 \%$ dilutions exhibited a sharp endothermic peak at $8^{\circ} \mathrm{C}$ corresponding to the $T_{m}$ of the oil (Figure 3 ). However, the second endotherm, seen at $-4^{\circ} \mathrm{C}$ in case of $20 \% \mathrm{w} / \mathrm{w}$ dilution, was shifted to $0^{\circ} \mathrm{C}$ upon increasing the dilution to $30 \% \mathrm{w} / \mathrm{w}$.

The release profiles of clonazepam (Figure 4) show that the $\mathrm{T}_{100 \%}$ values are $90 \mathrm{~min}, 240 \mathrm{~min}$, $360 \mathrm{~min}$ and $60 \mathrm{~min}$ for formulae I, IMa3, II and III respectively. When applying Peppas equation to formulae II and IMa3 the obtained $\mathrm{n}$ values were about 0.5 and $\sim 1$, respectively.

Visual observation revealed physical stability of the systems under the storage conditions for six months, without phase separation and no significant particle size changes $(\mathrm{p}>0.05)$. Furthermore, F2 values of the dissolution profiles, before and after storage, were all above $50 \%$ confirming systems stability.

Table 2. Compositions of selected nanostructured carriers.

\begin{tabular}{|c|c|c|c|c|c|c|c|}
\hline \multirow[b]{2}{*}{$\begin{array}{l}\text { Formula } \\
\text { code }\end{array}$} & \multirow{2}{*}{$\begin{array}{c}\text { IPM } \\
\text { conc. } \\
(\% \mathrm{w} / \mathrm{w})\end{array}$} & \multicolumn{2}{|c|}{ Surfactant } & \multicolumn{2}{|c|}{ Cosurfactant } & \multirow[b]{2}{*}{$\begin{array}{l}\text { Water } \\
(\% \mathrm{w} / \mathrm{w})\end{array}$} & \multirow{2}{*}{$\begin{array}{l}\text { Water to } \\
\text { Surfactant } \\
\text { ratio }\end{array}$} \\
\hline & & Type & $\begin{array}{l}\text { conc. } \\
(\% \mathrm{w} / \mathrm{w})\end{array}$ & Type & $\begin{array}{l}\text { conc. } \\
(\% \mathrm{w} / \mathrm{w})\end{array}$ & & \\
\hline I & 10 & Tween 80 & 35 & PG & 5 & 50 & 1.4 \\
\hline II & 16.66 & Cremophor EL & 41.66 & PG & 25 & 16.66 & 0.399 \\
\hline III & 23 & Cremophor EL & 30.7 & PEG200 & 23.15 & 23.15 & 0.75 \\
\hline IMa3 & 6.6 & $\begin{array}{c}\text { Tween } 80 \\
\text { Lecithin } \\
\end{array}$ & $\begin{array}{c}40 \\
13.3 \\
\end{array}$ & Ethanol & 6.6 & 33.33 & 0.625 \\
\hline
\end{tabular}

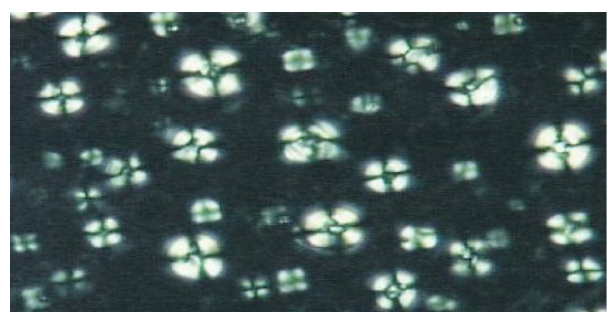

Figure 2. Polarized light microscopy of formula II.

Table 3. Physical characterization of selected nanocarriers (Mean $\pm S D, n=3$ ).

\begin{tabular}{cccccc}
\hline \multirow{2}{*}{$\begin{array}{c}\text { Formula } \\
\text { code }\end{array}$} & \multicolumn{3}{c}{ Particle size measurements } & Conductivity $(\mu \mathrm{s})$ & Viscosity (cp) \\
\cline { 2 - 4 } & Mean (nm) & D 90\% $(\mathrm{nm})$ & PDI & & \\
\hline I & $21.33 \pm 0.57$ & $23.33 \pm 1.15$ & $0.018 \pm 0.007$ & $1.87 \pm 0.055$ & $274.66 \pm 19.65$ \\
IMa3 & $54.66 \pm 4.51$ & $92.66 \pm 3.78$ & $0.1 \pm 0.0071$ & ------ & $356.33 \pm 31.67$ \\
II & $62.33 \pm 3.05$ & $95 \pm 2$ & $0.096 \pm 0.018$ & ------ & $400.4 \pm 30.55$ \\
III & $51.33 \pm 3.21$ & $90.66 \pm 1.52$ & $0.076 \pm 0.022$ & $0.03 \pm 0.002$ & $218.33 \pm 22.54$ \\
\hline
\end{tabular}




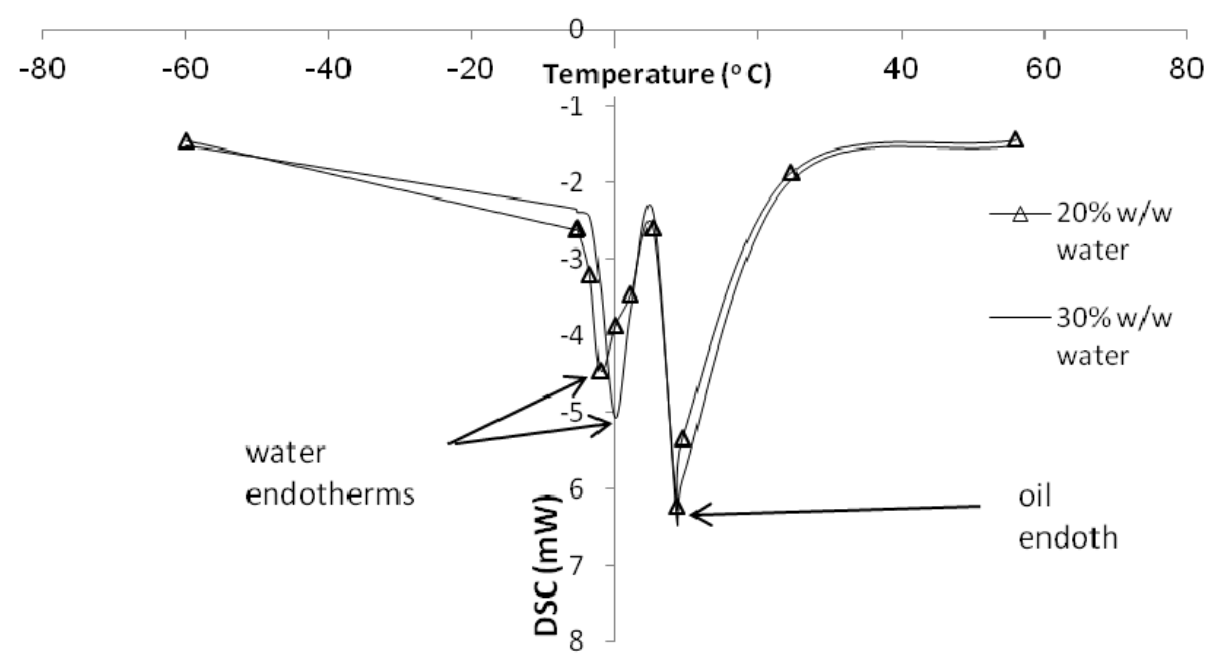

Figure 3. DSC thermogram of clonazepam microemulsion formula I.

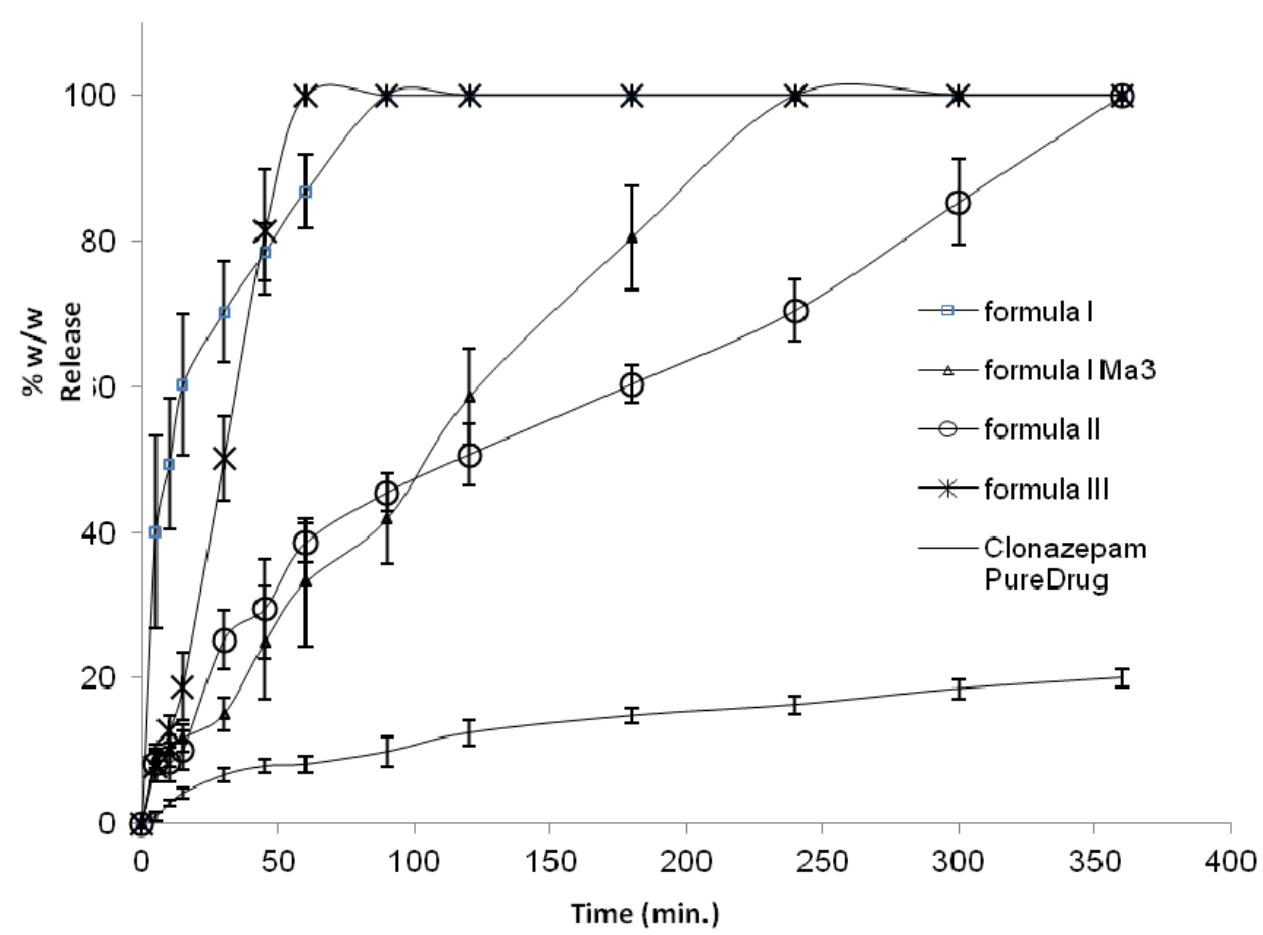

Figure 4. Release profiles of clonazepam formulae (Mean $\pm S D, n=3$ ).

\section{in-vivo pharmacokinetic and brain distribution \\ Plasma pharmacokinetic parameters:}

No significant differences were found between plasma $\mathrm{AUC}_{0-\infty}$ of various nasal nanocarriers and iv solution ( $\mathrm{p}>0.05$ ) or between plasma $\mathrm{AUC}_{0-\infty}$ of different nanocarriers (Table 4). Microemulsions I and III plasma profiles show two peaks, whereas only one peak was noticed in case of IMa3 and II (Figures 5A and B). Clonazepam nasal formulae show higher MRT than iv solution except for formula III. Besides, the calculated rate of elimination constant $\left(\mathrm{K}_{\mathrm{el}}\right)$ of each formula is significantly lower than that of $i v$ solution except for formula III $(\mathrm{p}<0.05)$. 


\section{Brain pharmacokinetic parameters:}

Intranasal clonazepam nanocarriers show significantly higher values for the brain AUC ${ }_{0-\infty}$ than that of $i v$ solution $(\mathrm{p}<0.05)$ especially in case of IMa3 and formula II exhibiting the highest AUC ${ }_{0-\infty}$ value (Table 5). Microemulsion formulae (I and III) have two peaks whereas only one peak is detected in case of formulae IMa3 and II (Figure 6A and B). Finally, higher DTE\% values are noticed with all nasal formulae than with $i v$ solution.

\section{Nasal irritation test}

Only mild dilatation in the blood vessels of the lamina propria with formula I, while the lamina propria was seen exhibited edema with severe blood vessel congestion in case of formula III (Figure 7A \& B respectively). Furthermore, a mild thickening in the mucosal layer accompanied with mild congestion of the lamina propria was noticed in case of formula IMa3 (Figure 8A). Finally, no histopathological changes exemplified by vascular congestion, subepithelial edema, necrosis, sloughing of epithelial cells or hemorrhage could be observed in case of liquid crystal formula II (Figure 8B).

\section{DISCUSSION}

The failure of IPM-Tween80-PEG200 combination to yield microemulsion can be attributed to its inability to make a balanced zero curvature. The bulkiness of Tween 80 - PEG 200 molecules, might have caused steric hindrance and prevent the geometrical orientation, fitting of PEG 200 within Tween 80 monolayer. On the other hand, the less bulky PG could be easily packed among Tween 80 molecules. However, Cremophor EL, with a less bulky nature, was easily packed with both PG and PEG 200. The shrinkage in domain seen when Cremophor EL replaced Tween 80, and PEG replaced PG, might be due to a lower hydrophilic lipophilic balance (HLB) in case of Cremophor EL - PEG combination.

Being too hydrophobic, lecithin was unable to form the spontaneous zero curvature required for microemulsion. So combining it with Tween 80 will reduce the interfacial tension of the system by adjusting HLB suitable for microemulsion formation (30). Sufficient interfacial film flexibility is achievable by the addition of short chain alcohols as ethanol (31).

The reported critical value $n c r$ for IPM (defined as the ratio between polar solvents to lecithin weights above which organogel separation occurred) equals 3 (32). A condition fulfilled in case of formula IMa3.

The viscosity increase accompanying higher water content in formula I versus formula III with respective water concentrations of 50 and 23.15 \%can be attributed to strong hydration of the hydrophilic chains of the surfactant which are interconnected through $\mathrm{H}$-bonds causing viscosity increase (33). However formulae II and IMa, with comparatively lower water content exhibit high viscosity values due to the liquid crystalline nature of formula II and the 3-D network of organogel formula IMa3.

The globule size range and PDI of different formulae indicates that the nanostructured carriers approached monodisperse stable systems with uniform size distribution (34). This will give a platform for a uniform absorption from nasal mucosa. The similarity in the rank between systems particle size and water to surfactant ratio was previously reported (35). The particular small particle size (less than $100 \mathrm{~nm}$ ) suggests their uptake into the neurons and supporting cells, via the intraaxonal route in the filia olfactoria (36).

Table 4. Plasma pharmacokinetic parameters (Mean $\pm \mathrm{SD}, \mathrm{n}=6$ ).

\begin{tabular}{|c|c|c|c|c|c|c|}
\hline $\begin{array}{l}\text { Formula } \\
\text { Code }\end{array}$ & $\mathrm{C}_{\max }(\mathrm{ng} / \mathrm{ml})$ & $\begin{array}{c}\mathrm{T}_{\max } \\
(\mathrm{min}) \\
\end{array}$ & $\begin{array}{c}\mathrm{AUC}_{0-8} \\
\text { (ng/ml.hr) }\end{array}$ & $\begin{array}{c}\mathrm{AUC}_{0-\infty} \\
\text { (ng/ml.hr) }\end{array}$ & MRT (hr) & $\mathrm{K}_{\mathrm{el}}\left(\mathrm{hr}^{-1}\right)$ \\
\hline I & $412.1 \pm 12.2$ & 10 & $347.6 \pm 11.9$ & $416.8 \pm 109.1^{\mathrm{a}}$ & $3.3 \pm 0.3$ & $0.188 \pm 0.003^{b}$ \\
\hline IMa3 & $483.0 \pm 17.3$ & 30 & $337.1 \pm 87.1$ & $432.1 \pm 51.4^{\mathrm{a}}$ & $3.3 \pm 0.4$ & $0.149 \pm 0.003^{b}$ \\
\hline II & $275.1 \pm 15.5$ & 15 & $273.6 \pm 65.8$ & $449.8 \pm 80.2^{\mathrm{a}}$ & $4.7 \pm 0.2$ & $0.096 \pm 0.001^{b}$ \\
\hline III & $418.0 \pm 18.7$ & 15 & $395.3 \pm 56.0$ & $443.9 \pm 69.9^{\mathrm{a}}$ & $2.7 \pm 0.1$ & $0.309 \pm 0.005$ \\
\hline $\begin{array}{l}\text { Intravenous } \\
\text { solution }\end{array}$ & - & - & $412.4 \pm 95.0$ & $486.1 \pm 52.2^{\mathrm{a}}$ & $3.0 \pm 0.6$ & $0.231 \pm 0.001^{\mathrm{b}}$ \\
\hline
\end{tabular}



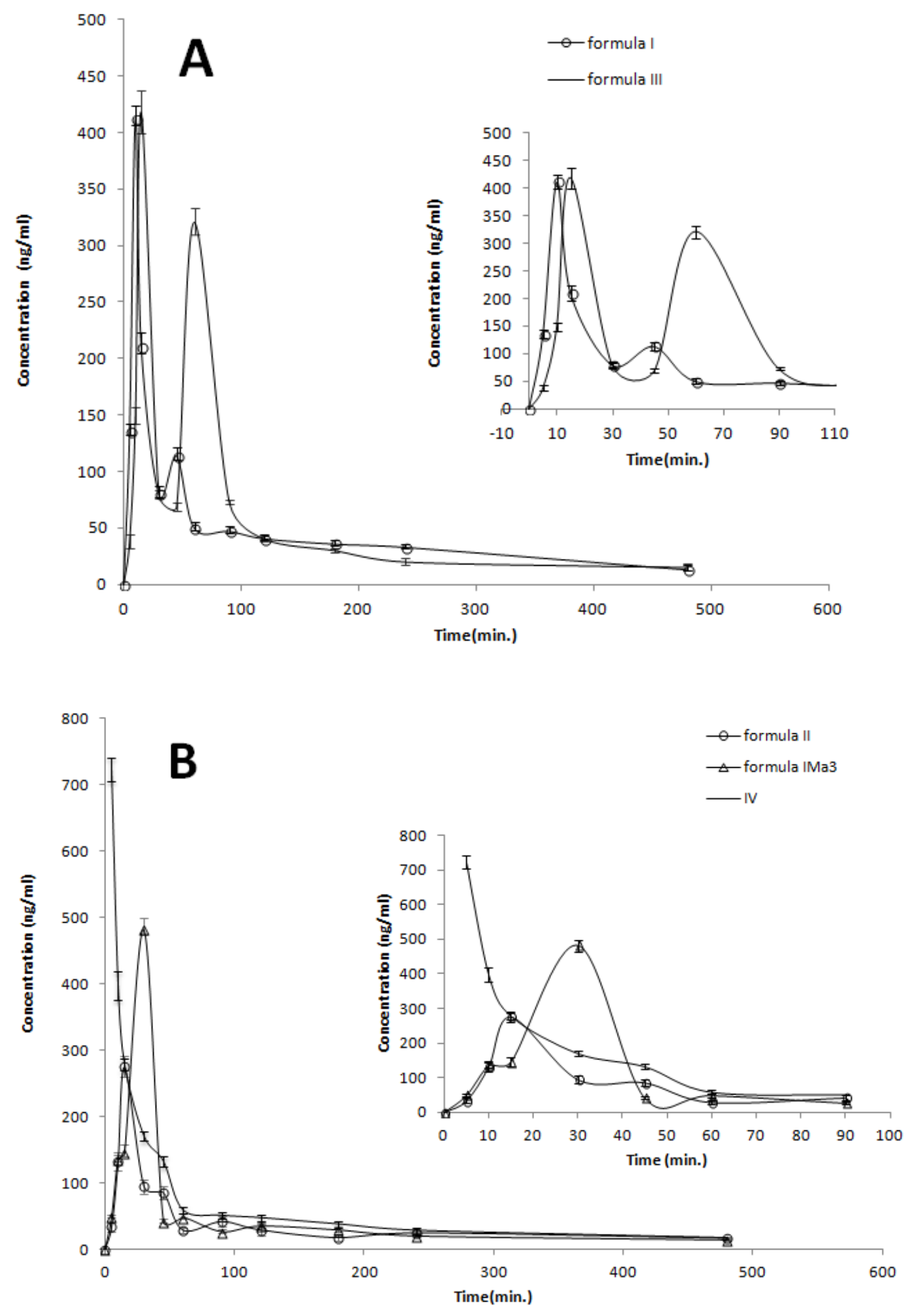

Figure 5. (A and B) Plasma concentration curves of clonazepam form nasal formulae compared to $i v$ solutions. $\mathrm{n}=6 /$ each time interval. 
Table 5. Brain pharmacokinetic parameters (Mean $\pm \mathrm{SD}, \mathrm{n}=6$ ).

\begin{tabular}{|c|c|c|c|c|c|c|c|}
\hline $\begin{array}{l}\text { Nasal } \\
\text { Formula } \\
\text { Code }\end{array}$ & $\mathrm{C}_{\max }(\mathrm{ng} / \mathrm{g})$ & $\begin{array}{l}\mathrm{T}_{\max } \\
(\min )\end{array}$ & $\begin{array}{l}\mathrm{AUC}_{0-8} \\
\text { (ng/g.hr) }\end{array}$ & $\begin{array}{l}\text { AUC }_{0-\infty} \\
\text { (ng/g.hr) }\end{array}$ & $\begin{array}{l}\text { MRT } \\
(\mathrm{hr})\end{array}$ & DTE $\%$ & DTP\% \\
\hline I & $331.6 \pm 13.6$ & 10 & $1107.6 \pm 98.7$ & $1689.8 \pm 18.9^{\mathrm{a}}$ & $4.0 \pm 0.2$ & $469.3 \pm 5.1$ & $78.7 \pm 2.9$ \\
\hline IMa3 & $284.4 \pm 15.4$ & 10 & $1613.1 \pm 87.3$ & $2588.1 \pm 22^{\mathrm{a}}$ & $5.1 \pm 0.9$ & $705.0 \pm 6.1$ & $96.8 \pm 1.9$ \\
\hline II & $321.8 \pm 28.4$ & 10 & $1408.2 \pm 67.2$ & $2407.4 \pm 15.2^{\mathrm{a}}$ & $5.3 \pm 0.7$ & $757.9 \pm 3.1$ & $86.8 \pm 1.3$ \\
\hline III & $2290.5 \pm 58.0$ & 10 & $1233.1 \pm 88.4$ & $1313.2 \pm 66.3^{\mathrm{a}}$ & $2.5 \pm 0.6$ & $459.6 \pm 2.1$ & $78.5 \pm 2.0$ \\
\hline $\begin{array}{l}\text { Intravenous } \\
\text { solution }\end{array}$ & $166.6 \pm 7.0$ & 30 & $280.1 \pm 24.0$ & $357.6 \pm 59.4^{\mathrm{b}}$ & $3.7 \pm 0.6$ & ---- & ----- \\
\hline
\end{tabular}

The higher conductivity seen with formula I than formula III can be attributed to its higher water content creating a conductive entity (37).

Two types of water are present in microemulsions: one, weakly bound to the surfactant, freezing at $0^{\circ} \mathrm{C}$ and called bulk or free water, while the second, is strongly bound at the interface, freezing below $0^{\circ} \mathrm{C}$, and termed bound or interfacial water (38). At early stages of dilution, microemulsions are known to be w/o, i.e. its water would freeze below $0^{\circ} \mathrm{C}$, which might or might not convert to o/w type. The appearance of water melting endotherm at $0^{\circ} \mathrm{C}$ at $30 \%$ dilution confirmed such an inversion in formula I at this specific dilution which explained the high conductivity value of the system.

The lipophilic nature of clonazepam with a partition coefficient $\log \mathrm{P}_{\text {(octanol/water) }}=2.41$ favored its residence in the oily phase. Hence, in formula III (w/o), clonazepam might have resided mainly in the external oily phase, in direct contact with the dissolution medium with a more rapid release than $\mathrm{o} / \mathrm{w}$ microemulsion (formula I).

The slower drug release exhibited by the liquid crystal (formula II) and organogel (formula IMa3) could be attributed to their high viscosity.

The obtained $\mathrm{n}$ values from Peppas equation indicated a diffusion release pattern from the liquid crystal (II) and zero order release from the lecithin organogel (IMa3).

The non-significant difference between the plasma AUC $0-\infty$ after both in and iv administration ( $>0.05)$, indicated high drug absorption by the nasal route. The double plasma peaks observed with formulae I and III could be interpreted by an initial direct absorption from the nasal cavity followed by a second oral absorption phase, post drug swallowing after in administration. On the other hand, the single $T_{\max }$ in case of IMa3 and II could confirm the absence of oral absorption due to the increased nasal residence, as a result of the relatively high viscosity of formulae (Figure $5 \mathrm{~A}$ and B). The higher values of MRT in case of clonazepam nasal systems, formulae I, IMa3 and II, than that of $i v$ solution, indicates a sustained drug release, a case not met with formula III containing PEG 200. In microemulsion, the cosurfactant hydroxyl group lied among the polar group of surfactant and neighboring water molecules, while the hydrocarbon groups are present among the apolar chain of the surfactant. However, not all cosurfactant molecules are fixed within interfacial region. A fraction will be distributed between the oil and water phases according to their relative solubilities (39). PEG 200, by its relative low polarity, might have helped drug solubilization in the continuous external oily phase of formula III, with subsequent possibility of facilitating clonazepam absorption via the biological environment. The significantly higher plasma $\mathrm{K}_{\mathrm{el}}$ of formula III containing PEG 200 could be justified by the cosolvent effect of PEG 200 helping in rapid drug elimination.

The increase in brain AUC $0-\infty$ of different nasal formulations in comparison to that of iv administration (3.6 -7.2 fold) confirms direct nose to brain transport via olfactory region.

The drug uptake into the brain following in administration, mainly, occurs via two pathways. One is the systemic pathway, by which some of the drug is absorbed into the systemic circulation and subsequently reaches the brain by crossing the BBB. The other is the olfactory way by which the drug partly travels from the nasal cavity to CSF and/or brain tissue (40-42). The presence of two peaks in brain concentration profile (Figure $6 \mathrm{~A}$ ) in case of formulae I and III, the first one appeared after $10 \mathrm{~min}$, can be related to direct nose-to-brain transport. The second one appears after $30 \mathrm{~min}$, similar to $i v$ administration, could be due to nose-to blood- to brain transport. The high DTE\% values of all nanocarriers confirm brain targeting. 

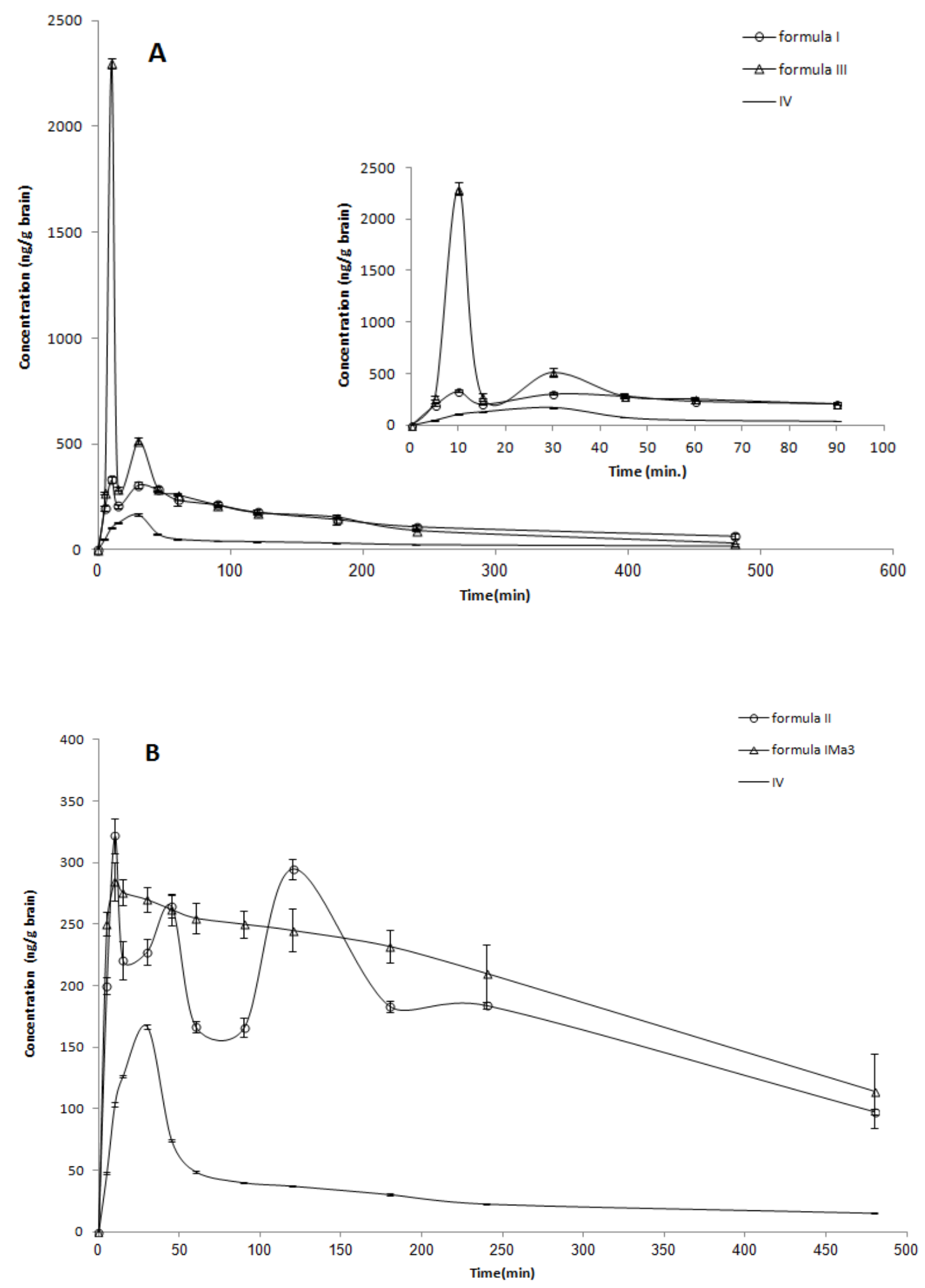

Figure 6 (A and B). Brain concentration curves of clonazepam form nasal formulae compared to $i v$ solutions. $n=6 /$ each time interval. 


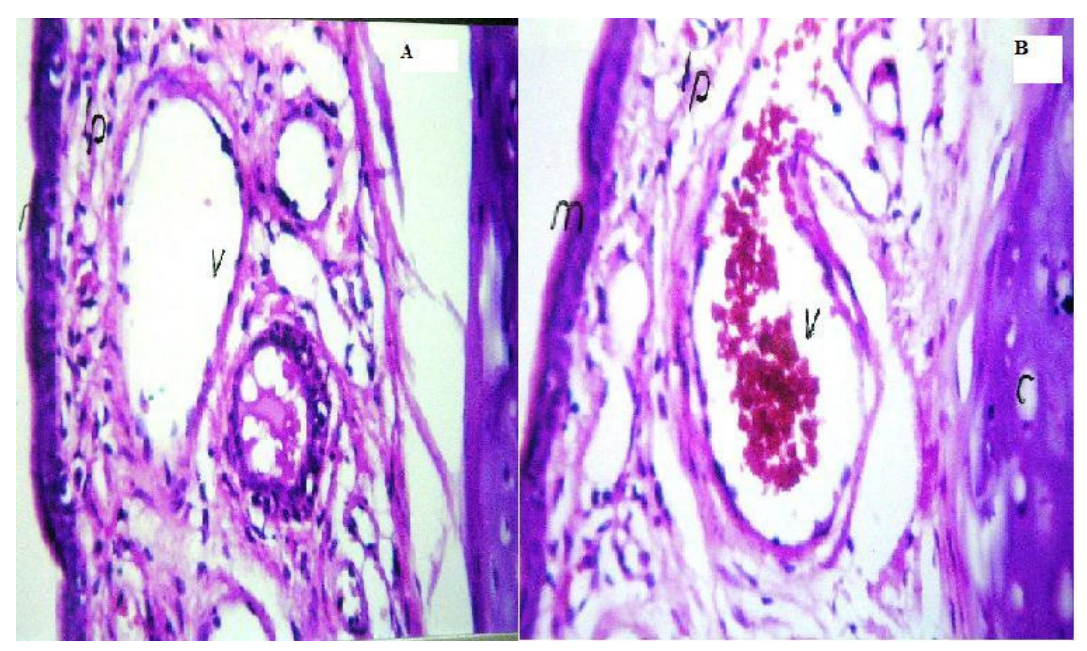

Figure 7. Light photomicrographs of the rat nasal mucosa following 14-day exposure to formula I (A) and formula III (B) $* \mathrm{~m}=$ mucosa, $\mathrm{v}=$ vessel, $\mathrm{l} \mathrm{p}=$ lamina propria, $\mathrm{c}=$ cartilaginous layer.

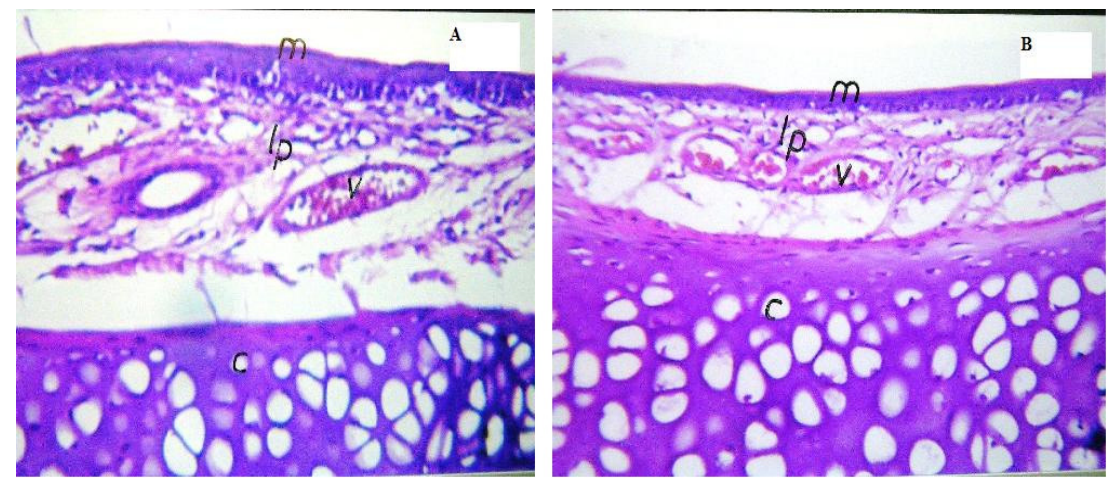

Figure 8. Light photomicrographs of the rat nasal mucosa following 14-day exposure to formula IMa3 (A) and formula II (B) *m=mucosa, v=vessel, lp=lamina propria, c=cartilaginous layer.

The relatively high DTP\% values shown with formulae IMa3 and II, with the absence of the second peak corresponding to the nose - to blood - to brain transport, indicate a major drug transport via the nose. Formula III, in spite of having almost the same value of DTE and DTP \% as formula I, yet its MRT is the least, hence allowing a rapid and effective drug absorption followed by rapid elimination (high $\mathrm{K}_{\mathrm{el}}$ ). This was presumed to be due to PEG 200 physicochemical properties.

Besides, Mistry et al.(36) proved that different PEGs facilitated nasal mucosal penetration and cellular uptake more than Tween 80 , especially the low molecular weight ones. Liquid crystal, formula II, shows small variations in brain drug level due to gradual erosion of liquid crystal matrix. Prolonged drug level in the brain was obvious with this formula as well as with lecithin organogel formula (IMa3).

The ethanol content of IMa3 might have been the cause of blood vessels congestion and thickened mucosa seen in the histopathological examination of this formula. On the other hand, PEG 200 was reported to be an efficient nasal penetration enhancer facilitating cellular uptake (36). This was reflected, in our study, on the affection of nasal mucosal integrity causing edema and severe congestion of the blood vessels in case of formula III. Consequently, a very high brain $\mathrm{C}_{\max }$ was seen with this formula.

On the other hand, formula II was found to be safe to the nasal mucosa. Cremophor EL, the main component of this formula, was previously reported to be less irritating than PEG derivative for nasal mucosal tissue (43). The high nasal residency of this formula, due to its liquid crystal 
nature, did not cause any irritation signs. Formula I exhibited mild irritation. It was similar in composition to formula II except for the nature of surfactant (Tween 80 versus Cremophor EL), confirming the superior safe nature of the later surfactant.

\section{CONCLUSION}

From the above results, it can be concluded that clonazepam brain deposition was possible after in administration of different nanostructured carriers. The composition of different formulae affected all pharmacokinetic parameters except brain $T_{\max }$ which was altered by the route of administration only. Moreover, lecithin based organogel and liquid crystal carriers delivered a high controlled clonazepam concentrations to the brain, with the later showing no histopathological changes to the nasal mucosa after 14 days administration.

\section{REFERENCE}

1. Bernacki J, Dobrowolska A, Nierwińska K, Małecki A. Physiology and pharmacological role of the blood-brain barrier. Pharmacol Rep, 2008;60(5): 600-22.

2. Sakane T, Tanaka C, Yamamoto A, Hashida M, Sezaki $\mathrm{H}$, Ueda $\mathrm{H}$. The effect of polysorbate 80 on brain uptake and analgesic effect of D-kyotorphin. Int J Pharm, 1989; 57:77-83.

3. Narang AS, Delmarre D, Gao D. Drug encapsulation in micelles and microemulsions. Int J Pharm, 2007; 345:9-25.

4. Gupta U, Jain NK. Non-polymeric nano-carriers in HIV/AIDS drug delivery and targeting. Advanced Drug Delivery Reviews, 2010; 62:478-490.

5. Kumar A, Sharma P, Chaturvedi A, Jaiswal D, Bajpai M, Choudhary M,et al. Formulation development of sertraline hydrochloride microemulsion for intranasal delivery. International Journal of ChemTech Research,2009; 1(4) :941-947.

6. Wilson Quevedo, Marcel Petri, Gerhard Busse, and Simone Techert. On the mechanism of photoinduced phase transitions in ternary liquid crystal systems near thermal equilibrium. The Journal of Chemical Physics, 2008; 129(024502):1-10.

7. Yao J, Zhou JP, Ping QN, Lu Y, Chen L. Distribution of nobiletin chitosan-based microemulsions in brain following i.v. injection in mice. Int J Pharm, 2008; 352:256-262.

8. Be'duneau A, Saulnier P, Benoit JP. Active targeting of brain tumors using nanocarriers. Biomaterials, 2007; 28: 4947-4967.
9. Nielsen L.S., Lene Schubert, Jens Hansen . Bioadhesive drug delivery systems: I. Characterisation of mucoadhesive properties of systems based on glyceryl mono-oleate and glyceryl monolinoleate. Eur. J. Pharm. Sci, 1998; 6:231-239.

10. Chung H., Kim J., Um Y.J., Kwon I.C., Jeong S.Y. Self-assembled" nanocubicle" as a carrier for peroral insulin delivery. Diabetologia, 2002; 45:448-451.

11. Patel P.V., Patel J.B., Dangar R.D., Patel K.S., Chauhan K. N. Liquid Crystal Drug Delivery System. International Journal of Pharmaceutical and Applied Sciences, 2010; 1:118-123.

12. Chang C.-M., Bodmeier R. Low viscosity monoglyceride-based drug delivery systems transforming into a highly viscous cubic phase. Int. J. Pharm, 1998; 173:51-60.

13. Costantino HR, Illum L, Brandt G, Johnson PH, Quay SC. Intranasal delivery: Physicochemical and therapeutic aspects .Int J Pharm,2007; 337:124.

14. Li L, Nandi I, Kim KH. Development of an ethyl laurate-based microemulsion for rapid-onset intranasal delivery of diazepam. Int J Pharm, 2002; 237:77-85.

15. Zaki NM, Awad GAS, Mortada ND, Abd ElHady SS. Rapid-onset intranasal delivery of metoclopramide hydrochloride: Part I. Influence of formulation variables on drug absorption in anesthetized rats. Int J Pharm, 2006; 327: 89-96.

16. Arumugam K., Subramanian GS., Mallayasamy S R., Averineni R K.,Reddy M S., Udupa N. A study of rivastigmine liposomes for delivery into the brain through intranasal route. Acta Pharm, 2008; 58: 287-297.

17. Pardridge WM. Blood-brain barrier delivery. Drug Discov Today, 2007; 12(1/2):54-61.

18. Candace LG, Pollock GM. Nasal Drug administration: potential for targeted central nervous system delivery. J Pharm Sci, 2005; 94:187-195.

19. Cartt S, Medeiros D. Wilson Sonsini Goodrich \& Rosati. 2007. IPC8 Class: AA61K912FI and USPC Class: 42443.

20. Aboofazeli R, Lawrence MJ. Investigations into the formation and characterization of phospholipid microemulsions. II. Pseudo-ternary phase diagrams of systems containing water-lecithinisopropyl myristate and alcohol: influence of purity of lecithin. Int J Pharm, 1994; 106:51-61.

21. Zhang P, Liu Y, Feng N, Xu J. Preparation and evaluation of self-microemulsifying drug delivery system of oridonin. Int J Pharm, 2008; 355: 269276.

22. Niels Mygind and Ronald Dahl. Anatomy, physiology and function of the nasal cavities in health and disease. Advanced Drug Delivery Reviews, 1998; 29(1-2): 3-12.

23. Peppas, N.A. Analysis of fickian and non-fickian drug 
release from polymers. Pharm Acta Helv, 1985; 60: 110-111.

24. Vyas TK, Babbar AK, Sharma RK, Singh S, Misra A. Intranasal Mucoadhesive Microemulsions of Clonazepam: Preliminary Studies on Brain Targeting. J Pharm Sc, 2006; 95:1-11.

25. Wagner JG, Nelson E. Percent absorbed time plots derived from blood level and/or urinary excretion data. J Pharm Sci, 1963; 52:610-611.

26. Miyamoto, M., Natsume, H., Iwata, S., Ohtake, K., Yamaguchi, M., Kobayashi, D., Sugibayashi, K., Yamashina, M., Morimoto, Y. Improved nasal absorption of drug using poly-1-arginine: Effect of concentration and molecular weight poly-Larginine on the nasal absorption of FITC-dextran in rats, Eur. J. Pharm. Biopharm. 2001; 52: 21-30.

27. Banchroft , J.D. ; Stevens , A. And Turner, D.R.THEORY AND PRACTICE OF HISTOLOICL TECHNIQUES. 1996: Fourth Ed. Churchil Livingstone , New york, London, San Francisco, Tokyo.

28. Yuan J. Estimation of variance for AUC in animal studies. J Pharm Sci 1993; 82: 781-783.

29. Shah VP, Tsong Y, Sathe P, Liu JP. In vitro dissolution profile comparison - statistics and analysis of the similarity factor. Pharm Res, 1998; 15: 889-896.

30. Moreno MA, Ballesteros MP, Frutos P. Lecithinbased oil-in-water microemulsions for parenteral use: pseudo ternary phase diagrams, characterization and toxicity studies. J Pharm Sci, 2003; 92: 1428-1437.

31. Paolino D, Massimo F. Lecithin microemulsions for the topical administration of ketoprofen: percutaneous adsorption through human skin and in vivo human skin tolerability. Int J Pharm, 2002; 244:21-31.

32. Kumar R, Katare OP. Lecithin Organogels as a Potential Phospholipid-Structured System for Topical Drug Delivery: A Review AAPS PharmSciTech, 2005; 6 (2):E298-E310.

33. Boonme P, Krauel K, Graf A, Rades T, Junyaprasert VB. Characterization of
Microemulsion Structures in the Pseudoternary Phase Diagram of Isopropyl Palmitate/Water/Brij 97:1-Butanol. AAPS PharmSciTech, 2006; 7 (2) Article 45: E1-E6.

34. Kumar M, Misra A, Babbar AK, Mishra AK, Mishra P, Pathak K. Intranasal nanoemulsion based brain targeting drug delivery system of risperidone. Int J Pharm, 2008;358: 285-291

35. Gupta S, Brouwer P, Bandyopadhyay S, Patil S, Briggs R, Jain J, Seal S. TEM/AFM Investigation of Size and Surface Properties of Nanocrystalline Ceria. Journal of Nanoscience and Nanotechnology, 2005; 5: 1101-1107.

36. Mistry A, Stolnik S, Illum L. Nanoparticles for direct nose-to-brain delivery of drugs. Int J Pharm, 2009; 379: 146-157.

37. Alany RG, Tucker IG, Davies NM, Rades T. Characterizing colloidal structures of pseudoternary phase diagrams formed by oil/water/ amphiphile systems. Drug Dev Ind Pharm, 2001;27 :31-38.

38. Garti N, Aserin A, Tiunova I, Fanun M. A DSC study of water behavior in water-in-oil microemulsions stabilized by sucrose esters and butanol. Colloids Surf A, 2000;170:1-18.

39. Resende KX, Corrêa MA, de Oliveira AG, Scarpa MV. Effect of cosurfactant on the supramolecular structure and physicochemical properties of nonionic biocompatible microemulsions. Brazilian J Pharm Sc, 2008; 44(1): 35-42

40. Illum L. Transport of drugs from nasal cavity to central nervous system. Eur J Pharm Sci, 2000; 11: 1-18.

41. Illum L. Nasal drug delivery: problems, possibilities and solutions. J Controlled Rel, 2003; 87: 187-198.

42. Vyas TK, Shahiwala A, Marathe S, Misra A. Intranasal drug delivery for brain targeting. Curr Drug Deliv, 2005; 2: 165-175.

43. Choi Yong Moon, Li Lianli ,Kim Kwon H. Transnasal anticonvulsive compositions and modulated process. United States Patent: 7,132,112, 2006; November 7. 